IZA DP No. 6553

Early Interventions and Disability Insurance:

Experience from a Field Experiment

Per Engström

Pathric Hägglund

Per Johansson

May 2012 


\title{
Early Interventions and Disability Insurance: Experience from a Field Experiment
}

\author{
Per Engström \\ Uppsala University, UCLS and IFAU \\ Pathric Hägglund \\ Swedish Social Insurance Inspectorate (ISF) and SOFI \\ Per Johansson \\ Uppsala University, UCLS, IFAU, ISF and IZA
}

\author{
Discussion Paper No. 6553 \\ May 2012
}

IZA

P.O. Box 7240

53072 Bonn

Germany

Phone: +49-228-3894-0

Fax: +49-228-3894-180

E-mail: iza@iza.org

\begin{abstract}
Any opinions expressed here are those of the author(s) and not those of IZA. Research published in this series may include views on policy, but the institute itself takes no institutional policy positions.

The Institute for the Study of Labor (IZA) in Bonn is a local and virtual international research center and a place of communication between science, politics and business. IZA is an independent nonprofit organization supported by Deutsche Post Foundation. The center is associated with the University of Bonn and offers a stimulating research environment through its international network, workshops and conferences, data service, project support, research visits and doctoral program. IZA engages in (i) original and internationally competitive research in all fields of labor economics, (ii) development of policy concepts, and (iii) dissemination of research results and concepts to the interested public.
\end{abstract}

IZA Discussion Papers often represent preliminary work and are circulated to encourage discussion. Citation of such a paper should account for its provisional character. A revised version may be available directly from the author. 


\section{ABSTRACT}

\section{Early Interventions and Disability Insurance: Experience from a Field Experiment ${ }^{\star}$}

This paper estimates the effects of early interventions in the Swedish sickness insurance system. The aim of the interventions is to screen and, further to, rehabilitate sick listed individuals. We find that the early interventions - in contrast to what is expected - increase the inflow into disability benefits by around 20 percent. In order to explain the results, we develop a simple theoretical model based on asymmetric information of the health status. The model predicts that the treatment effect is larger for individuals with low incentives to return to work. In order to test this prediction we estimate effects for sick listed employed and unemployed separately. Consistent with the model's prediction, we find that the effect is larger for the unemployed than for the employed.

JEL Classification: C93, H51, H55, I18, J22

Keywords: monitoring, screening, vocation rehabilitation, disability insurance, sickness insurances, unemployment insurance, randomized experiment

Corresponding author:

Per Johansson

IFAU

Box 513

75120 Uppsala

Sweden

E-mail: per.johansson@ifau.uu.se

\footnotetext{
* Johansson acknowledges financial support from The Swedish Council for Working Life and Social Research FAS and the Swedish social insurance administration. The paper has benefited from comments by seminar participants at SEW St. Gallen, SSB Oslo and at the conference on Absenteeism and Social Insurance Utrecht University September 2011, Eva Deuchert, Laura Hartman, Edwin Leuven and Mats Persson and Olof Åslund.
} 


\section{Table of contents}

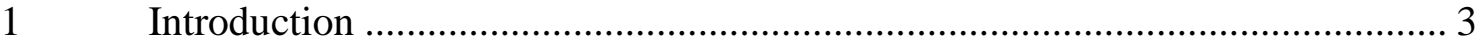

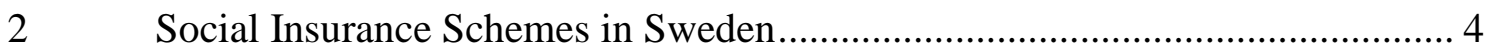

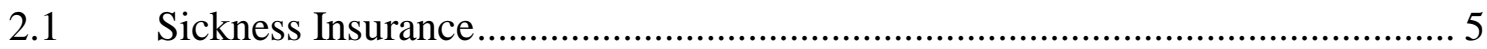

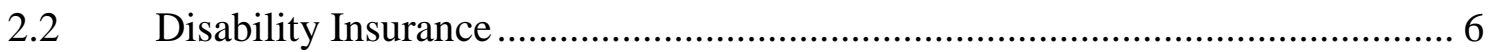

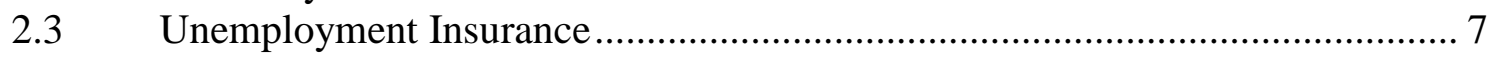

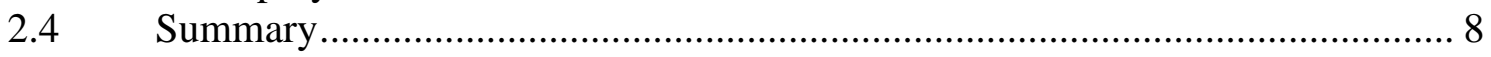

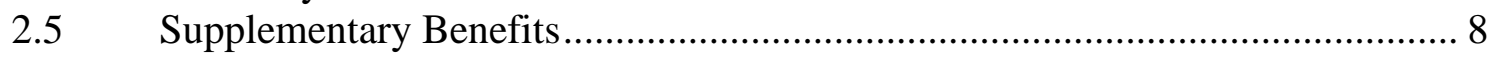

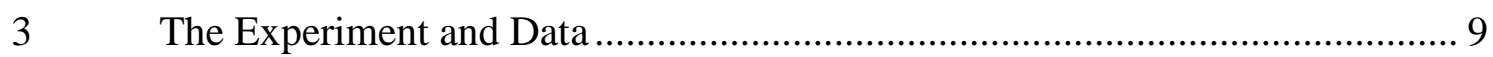

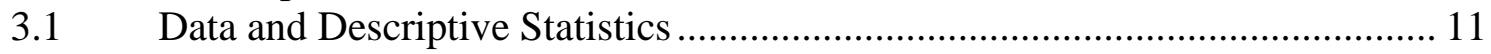

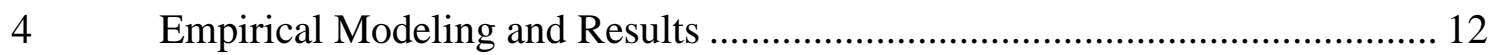

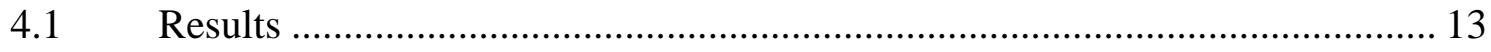

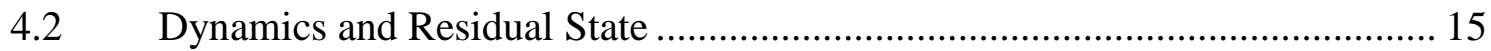

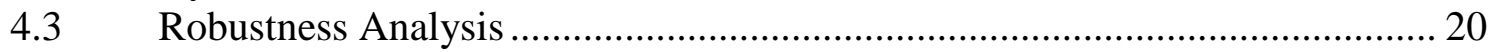

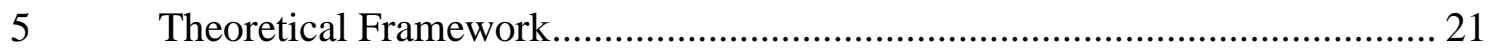

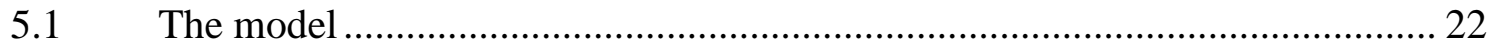

5.2 Optimal Choice of Communicated Health ..................................................... 23

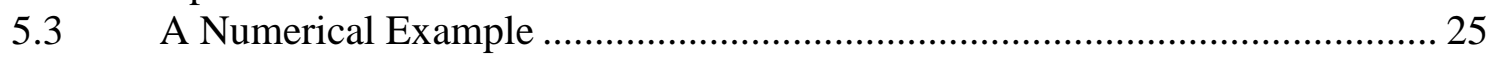

$6 \quad$ Effects for Unemployed and Employed ….............................................. 27

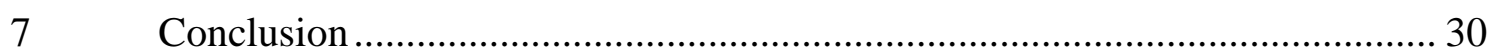

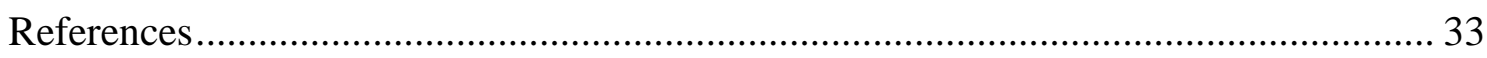

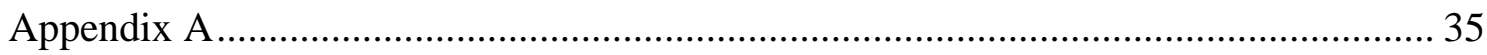

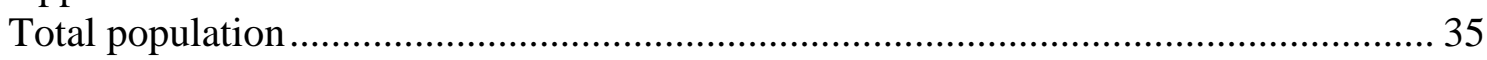

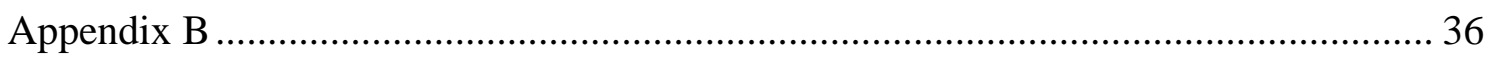

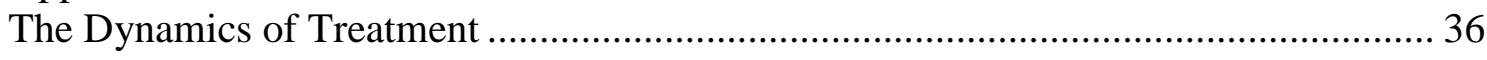

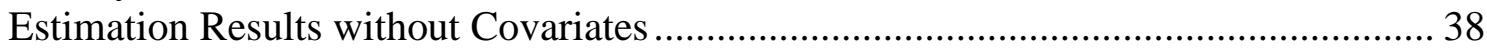




\section{Introduction}

In this paper we study the effects of early interventions by the Swedish Social Insurance Administration (SIA). The aim of these interventions is primarily to assess the individual's work capacity and possibilities for vocational rehabilitation. In the analysis we make use of a large ( 13,500 individuals) randomized experiment conducted in collaboration with SIA in 2007. The randomization was performed on the inflow of sick absent individuals. Individuals assigned to be treated were given priority to get two types of interventions during a 6-week period. The first, denoted Sassam, screens the working capacity of the individual and the need for vocational rehabilitation. The second, AM, is a formalized meeting between the sick reported individual, the SIA, and the employer where the possibility to return to alternative work tasks are discussed and appropriate vocational rehabilitation measures are decided upon. The individuals of the control group were not given priority to these activities during the 6 weeks, but were offered the same activities after the 6 weeks. The implication of the evaluation design is that the probability of receiving the interventions is higher in the treatment group.

The present paper adds important insights on why early interventions may be problematic if the intention is to reduce the inflow into disability benefits (DB). Autor and Duggan (2010) suggest that increasing employer responsibility and early intervention at the workplace are useful measures in reducing the inflow to DB. However, although intuitive and theoretically motivated, the strategy of early intervention in a sickness absence spell relies either on the presence of efficient backto-work strategies or on deterring effects from screening and monitoring. While the empirical literature offers no strong support for reduced sickness absence from different vocational rehabilitations, ${ }^{1}$ there is some evidence of reduced sickness absence from monitoring and time limits in sickness insurance. ${ }^{2}$ Since we lack data on the date of assignment to Sassam and AM, such an analysis is however not possible in the present experiment.

Two Swedish reports have been generated from the present experiment. Försäkringskassan (2010) concluded that those who were prioritized to Sassam and $\mathrm{AM}$ also received rehabilitation measures earlier than those not prioritized. Engström

\footnotetext{
${ }^{1}$ See, e.g., Elders et al. (2000), Bloch and Prins (2001), Alexandersson and Nordlund (2004), Andrén and Palmer (2004), Blank et al. (2008), Försäkringskassan (2007), and van Oostrom et al. $(2009,2010)$.

${ }^{2}$ See, e.g., Hesselius et al. (2005), Hägglund (2010), Johansson and Lindahl (forthcoming), and de Jong et al. (2011).
} 
et al. (2010) analyzed the length of the ongoing sick spell and found no effect from being prioritized to Sassam and AM on the exit rate.

In contrast to Engström et al. (2010), this paper focuses on the long-term effects and on the outcome in different labor market states. More specifically, we study the effects of the occurrence of i) sick absence, ii) unemployment, and iii) DB at the end of each month up to 15 months after the experiment. Our main finding is that individuals given priority to early interventions are more sick absent and have a higher probability to receive DB. In order to explain the results, we develop a simple theoretical model. In the model, the caseworkers do not observe individuals true health. Conditional on true health, wage and benefits, a sick-absent individual chooses a health-signal that maximizes the value of being on sickness benefits, taking into account that the transition rates to work and DB are affected by the signaled health. The effort of signaling bad health is assumed to be lower when the working capacity is being assessed by the caseworker. The model predicts that the treatment effect is larger for individuals with low incentives to return to work. In order to test this prediction we estimate effects for employed and unemployed separately. Consistent with the model's prediction, we find that the effect is larger for the unemployed than for the employed.

The report unravels as follows. In the next section, we give some background of the social insurances system together with a description of the major parts of the Swedish sickness insurance, disability insurance, and unemployment insurance. Section 3 describes the experiment and the data used in the empirical analysis discussed in section 4 . The theoretical model with the primary aim of increasing the understanding of the results seen in section 4 is set up in section 5. Based on separate analyses for unemployed and employed individuals, the theoretical model is tested in section 6. Section 7 finally concludes.

\section{Social Insurance Schemes in Sweden}

All workers (employed and unemployed) are covered by public sickness and disability insurance. Most workers are also covered by unemployment insurance . Unemployed individuals (covered or not by the unemployment insurance) have the possibility to make use of the sickness insurance. Until July 2008 there was no 
formal time restriction on the length of sickness absence in the sickness insurance. Such formal time restrictions exist in the unemployment insurance.

\subsection{Sickness Insurance}

Sickness insurance covers loss of income in case of work absence due to illness. For the employed, the employer compensates absence during the first 14 days (the first day being uncompensated). Beyond 2 weeks, the SIA is responsible for benefit payments. For the unemployed, the SIA steps in already from day 2 of the sick spell. The benefit level is 80 percent of foregone earnings. In 2007, the cap was set to SEK $25,187(\approx € 2,519)$ per month, and there was no time limit on sickness benefit. Since July 2008, there is a maximum benefit period of 2.5 years.

During the first 7 days of sick leave, it is in practice up to the individual to decide whether (s)he is ill and the extent to which this warrants absence from work. The individual merely has to inform the employer or the SIA that he or she is ill. As of the eighth day a medical certificate is required. For sick leave continuing longer than 2 weeks the employer notifies the SIA about continuation. The SIA sends a letter to the insured with a form and a request for a medical certificate. A medical certificate is needed for sickness benefits paid by the SIA. The doctor indicates in the medical certificate the length and the extent of the sick leave that (s)he believes is needed. Based on the medical certificate the SIA determines the right to sick leave, a process that normally takes at least 1-2 weeks after the end of the employer sick pay period. When this first sick leave period with benefit from the SIA has expired, if necessary, a renewal certificate is issued. The renewal certificate is also sent to the SIA and a new assessment about the right to sickness benefits is made. When the renewal certificate expires and the insured is still sick, the process is repeated.

Based on the information in the medical certificate the SIA decides whether the illness causes reduced capacity for work (i.e., work inability). For those who have a job, the work inability is based primarily in relation to the current job. For those who are unemployed, work inability is assessed against jobs ordinarily available in the labor market. When caseworkers think that the medical certificate contains insufficient information, they have the opportunity to refer the certificate back to the doctor for completion. The proportion of cases where the SIA decides contrary to the doctor's recommendation is, however, small. During 2006 the request for sick pay 
was rejected in 1.5 percent of the inflow (Försäkringskassan, 2007). The percentage of rejections increased to 1.7 percent in 2008 and the proportion of revocations of sickness benefit is stable at 1 percent.

When there are doubts about the right to benefits and the need for rehabilitation, the caseworkers are obligated to refer the sick absent individual to an assessment meeting. The available assessment meetings are Sassam ${ }^{3}$ and $\mathrm{AM}^{4}$. Both are mandatory and failure to participate could lead to withdrawal of benefits. The purpose of Sassam and AM is twofold: first, by reviewing medical certificates and other documentations, the SIA confirms whether the working capacity is reduced due to illness. The evaluation could also uncover the need for vocational rehabilitation, which then leads to the second purpose, which is to initiate different types of vocational rehabilitations.

\subsection{Disability Insurance}

The criteria for receiving DB depend on the age of the individual. For individuals 30 years and older, an individual is entitled to benefits if the working ability is assessed as being reduced by at least 25 percent for at least 1 year. Benefits could be granted either fully or partially (25, 50, or 75 percent). Before 1 July 2008, DB could be either permanent or time limited up to 3 years. With the new rules, only permanent DB are allowed. For individuals below 30 years of age, only time-restricted DB are granted. A benefit period could be no longer than three years. When a benefit period expires it could be renewed after a new assessment of the working capacity.

Disability benefits can be obtained in either of two ways. The individual can apply for benefits and the caseworker can, even without the individual's consent, initiate an exchange from sickness benefits to DB. The granting of DB starts with the caseworker preparing a portfolio with the necessary documentation together with an assessment of what the outcome should be. A specialist at the SIA then checks the documentation and whether further information is needed. The specialist presents a

\footnotetext{
${ }^{3}$ Sassam, which is a Swedish abbreviation for "A formalized method for sick-leave investigation and rehabilitation," is an inperson meeting where the sick individual and the SIA have a structural discussion (based on a so-called SASSAS-map) of the situation. This structural discussion concerns questions dealing with benefit eligibility, i.e., medical diagnoses, working ability, and working tasks. It also involves questions not directly associated with the right to benefits, for instance social status and work motivation. The results from the assessment are used to decide on the eligibility and on how the sick leave will progress.

${ }^{4}$ The AM is a formalized meeting between the sick individual, the SIA, and at least one additional part, usually the doctor or the employer. If the sick individual is unemployed, representatives from the employment agency could participate. The purpose of the meeting is to evaluate the working capacity and the possibility to return to the existing or alternative work tasks at the employer. If necessary, appropriate vocational rehabilitation measures are decided upon. An AM meeting should be foregone by a Sassam investigation. The purpose of the AM is to reduce sick-spell length and increase the possibility to return to work. In contrast to Sassam, AM is legislated in law (see proposition 2002/03:89).
} 
report to a second caseworker who makes the decision and denotes a decision maker in the following. If eligible, (s)he furthermore decides on the degree of the working disability $(0,1 / 4,1 / 2,3 / 4$, or full) and on the benefit level (based on the suggestion in the portfolio from the caseworker). Although the final decision is made by the decision maker, the caseworker plays a key role in the process since (s)he prepares the portfolio, which includes the assessment of the outcome and because (s)he may even initiate the application to start with.

Full income-related DB amount to 64 percent of an average of the three highest previous gross yearly incomes during a fixed reference period that varies with age. For those with low previous income a fixed guarantee level applies. The benefit level then basically depends on how long the individual has lived in, and is expected to live in, Sweden. Full compensation at the guarantee level in 2007 corresponds to SEK 98,400 ( $\approx € 9840)$.

\subsection{Unemployment Insurance}

Unemployment benefits can be paid in two different ways, a fixed basic compensation or as an income-related amount based on previous earnings. To receive any compensation, the unemployed must be at least 20 years of age and fulfill: i) the basic condition, and ii) the work condition. The basic conditions are a set of rules for the unemployed. For instance, they state that he or she should be partially or completely unemployed and prepared to accept suitable job offers. The work condition specifies that the unemployed must have been employed approximately 6 out of the last 12 months preceding unemployment. If these requirements are met, the unemployed is qualified for the fixed basic compensation. To be eligible for the higher income-related compensation one also needs to have been a member of a unemployment insurance fund for at least 12 months from the first day of unemployment.

After an initial 7-day waiting period, the duration of a benefited unemployment spell is limited to 300 days (individuals with children under 18 years of age are entitled to an additional 150 days). After that, the unemployed is offered an activity program (Jobb-och utvecklingsgarantin). The individual entitles for another 300-day benefit period through fulfilling the work condition again. The replacement rate for the first 200 days is 80 percent of previous earnings up to a cap of a maximum of 680 
SEK ( $\approx 68)$ per day. ${ }^{5}$ Between day 201 and 300 (450), the compensation is 70 percent, and in the activity program the compensation is 65 percent of previous earnings.

\subsection{Summary}

The replacement rates are the least generous in the unemployment insurance and the replacement rates in the disability insurance are lower than replacement rates in Sickness insurance. Since the replacement rate in Sickness insurance is higher than in disability insurance most disabled individuals prefer to be on sickness benefits (SB) rather than DB. This means that any screening for DB often takes place late in a sickness absence spell and that most/all individuals on DB have a prehistory of long sickness absence. ${ }^{6}$ In this way, the Sickness insurance and disability insurance are intimately related in Sweden. A recent overview (OECD, 2009) shows that Sweden had the second highest number of lost working days due to sickness and disability among OECD countries in 2007; more than 25 days per employee per year. In the US, the corresponding figure is 9 days.

\subsection{Supplementary Benefits}

Besides compensation from the public transfer system, most employed are also entitled to additional compensation from agreements between the social partners. ${ }^{7}$ As sick absent, these insurances top up the compensation below the cap up to a maximum of 90 percent of forgone earnings. Above the cap, total compensation amounts to 80-90 percent of foregone earnings the first year of the sick spell. About 90 percent of those in the working age population are covered by these supplementary benefits (Sjögren Lindquist and Wadensjö, 2007).

If the individual receives $\mathrm{DB}$, the collectively agreed insurances top up the compensation from the public insurance system to a maximum of 85 percent up to a cap of SEK 307,500 ( $\approx € 30,750)$. Total compensation is lower above the cap. Similar to above, almost everyone is entitled to these benefits. All in all, the total

\footnotetext{
${ }^{5}$ The cap is set relatively low; it is effective for approximately 50 percent of the unemployed and for 75 percent of the labor force.

${ }^{6}$ For those who were granted DB in 2007 and received sickness benefits up to the start date of receiving DB, the median sickness absent period was 789 days.

${ }^{7}$ These benefits mostly consist of four spheres of agreement: i) central government employees, ii) municipal and county council employees, iii) white-collar workers in the private sector, and iiii) blue-collar workers in the private sector. For more details on design of agreement-based insurance schemes, see Sjögren Lindquist and Wadensjö (2006).
} 
compensation when being sick absent more than 361 days is very similar to the benefits as disabled for all spheres of agreement.

Finally, as unemployed, the agreement-based insurance schemes could top up compensation to a maximum of 80 percent of previous earnings. To qualify for these insurances, the unemployed generally needs to be of a certain age and/or has been working at the workplace for a certain number of years. As a consequence, the share of unemployed entitled to these benefits is lower than the corresponding shares among sick reported and DB receivers.

In summary, the generosity of the agreed-based insurance schemes correlates with those of the public transfer system. They are most generous in case of sickness absence, and less generous when unemployed.

\section{The Experiment and Data}

In 2007, the SIA had a policy to screen individuals early in the sick spell in order to identify those potentially in need of active rehabilitation. Based on the screening, two groups of individuals were identified: the first group consisted of individuals with typically vague diagnoses (e.g., musculoskeletal and psychological disorders). These individuals were potentially after some further analysis assigned to Sassam and AM. The second group had less vague diagnoses (e.g., bone fractures, myocardial infarction, etc.) where the doctor rather easily could judge the time until return to work without active (vocational) measures. This experiment concerns the first group, that is, those in need of further assessment.

The experiment stems from the group of individuals screened in the period between 5 November and 14 December 2007. At the time of the screening, the sick spells had typically been ongoing for $2-5$ weeks, but some variation exists. ${ }^{8}$ Ninetyfour percent of the spells, however, were initiated in the period between 1 September and 30 November. During this period, a total of 87,136 individuals started a sick spell. Among these, 23,013 initial screenings were performed between 5 November and 14 December. The remaining 64,123 sick spells were either terminated during the first two weeks or screened before or after these dates. Of those screened, 13,547 were considered to be in need of further assessment. These individuals represent the

\footnotetext{
${ }^{8}$ Ninety percent of the spells had been ongoing for 1-10 weeks. The median number of weeks was 3 weeks and the average number of weeks was less than 4.
} 
experiment population. The rest, almost 10,000 individuals, were hence considered in no need for assessment and potentially early intervention. Based on the day of birth, the experiment population was (randomly) divided into two groups. The treatment group (6,517 individuals) was further assessed and given priority to Sassam when thought necessary. The control group $(7,030)$ had to wait for at least 45 days for the same treatment. We refer to these groups as the S-treated and the Scontrols.

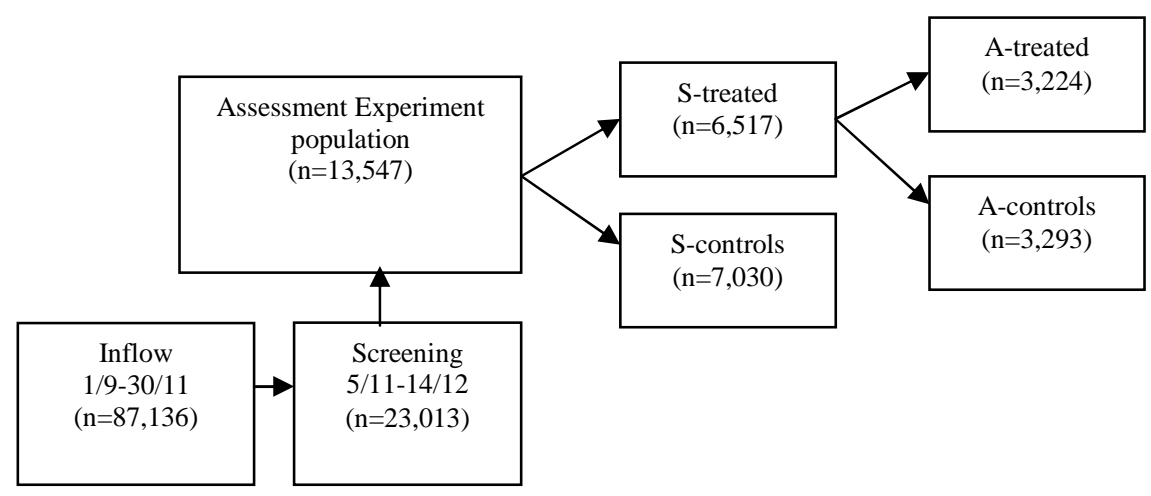

Figure 3. The experiment. S-treated individuals born on an even day and A-treated are individuals born on an even day and even month

Furthermore, among those given priority to Sassam (the S-treated), an additional randomization was performed. Individuals born in an even month were given priority to an AM (A-treated: 3,224 individuals), while the rest were set on hold for at least 45 days (A-controls: 3,293 individuals). In sum, the experiment consists of two separate experiments and three "randomly" assigned groups: (1) even day/even month, a potentially early Sassam/early AM; (2) even day/odd month, a potentially early Sassam/postponed AM; (3) odd day, a potential Sassam and AM are postponed. Figure 3 gives an illustration of the experiment.

The experiment design does not allow control over who receives intervention and when. These decisions are made by the caseworker. However, the group classification generates systematic differences in the availability and timing of the interventions (Sassam and AM). The caseworkers were instructed to work as usual. That is, belonging to a prioritized group or not, Sassam and AM were only performed when thought necessary.

Note that if the initial screening made by the caseworkers is based on the individuals' future sickness absence and dates of birth, the randomization will be 
distorted. Individuals born on an even day could, for example, be screened out if caseworkers did not want to make an intervention for this person. There are, however, two reasons why we do not think this is a problem. Most often caseworkers screening is not the same as caseworkers doing the assessment, and only the caseworkers selecting the treated (i.e., performing the randomization) were informed about the selection criterion. Secondly, and more important, it was not mandatory for the caseworker to assess a person if randomized to be treated (S-treated or Atreated).

All in all, we believe that making use of birth date as randomization devise is not a problem. But since we have access to data on all individuals with sickness spells starting in the period (see the inflow in Figure 3) when the experiment was conducted, we can perform sensitivity analysis where we estimate intention to treat effects for the 87,136 individuals who had a possibility to be assessed in the period.

\subsection{Data and Descriptive Statistics}

The outcomes of interest in this study are the occurrence of sickness absence, unemployment, and receiving DB up to 15 months after the experiment was conducted. In the analysis, we use data from the SIA that combine information from several data sources. First of all, data from the caseworker administration system, containing information of when and if Sassam and AM were performed, are linked to the benefit payment register (both disability and sickness benefits). Spell information on unemployment from the public employment services were then merged to these data. The registers also include basic individual information on gender, age, and educational level.

Descriptive statistics on the experimental population is presented in Table 1. From this table we can see that the share of individuals born on an even day (S-treated) and the share born on an even day in an even month (A-treated) is 48.1 and 49.5 percent, respectively. This is almost exactly the same shares as for the total population (see Appendix A) and close to what is theoretically expected $(179 / 365.25=0.490$ and $89 / 179=0.497$ ). This provides some evidence that caseworkers have not intentionally made the screening to the experiment population on the date of birth. The mean differences between treated and controls are overall very small. There are, however, some statistically significant differences worth discussing. 
The share of women among the S-treated is higher than among the S-controls, and the S-treated are also younger on average. The perhaps most problematic difference is the fact that the S-treated have on average more historic days on sickness absence than the S-controls. No significant differences are found between A-treated and Acontrols.

Table 1. Descriptive statistics for the experimental population (all cases assessed as active in the screening 5 November - 14 December 2007), averages

\begin{tabular}{lcccccc}
\hline & S-treated & S- control & t-test & A-treated & A-control & t-test \\
& & & & & & \\
\hline Women & 0.60 & 0.58 & 2.66 & 0.61 & 0.60 & 0.95 \\
Age & 44.3 & 44.7 & -2.23 & 44.3 & 44.2 & 0.35 \\
& $(0.14)$ & $(0.14)$ & & $(0.20)$ & $(0.20)$ & \\
Compulsory & 0.19 & 0.19 & -1.04 & 0.18 & 0.19 & -1.06 \\
Upper secondary & 0.52 & 0.53 & -0.78 & 0.53 & 0.52 & 0.87 \\
University & 0.29 & 0.28 & 1.70 & 0.29 & 0.29 & 0.03 \\
Sick-leave & 228 & 217 & 2.01 & 233 & 224 & 1.00 \\
history (days) & $(4.26)$ & $(4.03)$ & & $(6.18)$ & $(5.87)$ & \\
Unemployment & 493 & 493 & 0.01 & 492 & 495 & -0.19 \\
history (days) & $(9.01)$ & $(8.67)$ & & $(12.76)$ & $(12.72)$ & \\
Disability benefit & 0.53 & 0.53 & 1.17 & 0.54 & 0.52 & 1.78 \\
history (days) & $(0.01)$ & $(0.01)$ & & $(0.01)$ & $(0.01)$ & \\
Unemployed (at sick- & 0.12 & 0.11 & 0.27 & 0.11 & 0.12 & -0.31 \\
spell start) & & & & & & \\
Share & & 0.481 & 1.12 & & 0.495 & 0.09 \\
Sample size, N & 6,517 & 7,030 & & 3,224 & 3,293 & \\
\hline
\end{tabular}

Notes: Standard deviation is given within parenthesis. t-test tests for mean differences between the two groups (treated and controls). ${ }^{\mathrm{a}}$ Net days since $1995 .{ }^{\mathrm{b}}$ Gross days from 2000.

\section{$4 \quad$ Empirical Modeling and Results}

Interest is in analyzing effects on prevalence of employment, sickness, and DB 15 months after the experiment was conducted. An individual can be part time on sickness and disability benefits and part time working/unemployed. As a consequence we do not consider the three states as mutually exclusive. Unfortunately, there is no spell information on employment. The implication of this is that if an individual is not observed as being unemployed, sick, or disabled we do not know if the individual is working a certain month. Potentially the individual has left the labor force instead. A reasonable assumption, however, is that the vast majority of those in this "residual state" among those employed at the beginning of the sickness absent spell return to work if not unemployed or on sickness and DB. As 
we have information on yearly income from work this maintained assumption, of resumption to employed if no longer being unemployed or on sickness or disability benefits, is possible to investigate.

Effects from the treatment 15 months after the experiment was conducted are provided in section 4.1. In section 4.2 we study the dynamics by presenting the effect for each of the 15 months. We furthermore investigate the assumption of resumption to employment for employed individuals in the residual state. Finally, section 4.3 provides a sensitivity analysis.

\subsection{Results}

Since individuals naturally recover from an illness there is a natural outflow from the sickness absence for both treated and controls. The weakly hazard rate in the control group (not reported here) is quite constant for the first 60 days: around 4 to 4.5 percent. This means that around $2,000(7,030 * 0.045 * 6=1,899)$ individuals in the control group have left sickness absence before having a chance of receiving Sassam. One consequence of this natural outflow is that only 45 percent and 31 percent in the treatment and control groups, respectively, received Sassam. The corresponding shares in the AM-experiment were 30 and 26 percent (the share of treated for both groups each month in the 15 months follow-up period is provided in Appendix B).

This natural dropout from sickness absence makes it possible to estimate the effect of Sassam and AM by making use of a WALD or a two-stage least squares estimator (2SLS). In the situation of heterogeneous treatment effects that depend on the length of the sickness absence spell, a consequence of the design is that the 2SLS estimator does not estimate the average treatment effect from Sassam or AM for the population of sickness benefits recipients. Instead the estimator provides an estimate of the local average treatment effect (LATE) (Imbens and Angrist, 1994) for the population who would make use of Sassam and AM if being offered Sassam and AM early but not if being offered later on.

Table 2 presents the effects on the status 15 months after the screening. All estimations control for differences in covariates; however, these results are very similar to those when no control variables are added to the regressions (see Table C1 
in Appendix C). ${ }^{9}$ The table has two panels. The top panel concerns the effect of Sassam and the bottom the results of AM.

The results from the first-step estimations are presented in column (1) in the first row of each panel. These results confirm the pattern seen in the raw data. Belonging to the prioritized groups involves a 16.4 and 4.4 percentage point higher probability of receiving Sassam and AM respectively.

The reduced form, or intent-to-treat, estimates are presented in the second row of the two panels. No significant effects are found in the AM experiment. In the Sassam experiment, the effect on both sickness absence and unemployment is close to zero. However, the result shows an 0.8 percentage point or an $18(0.8 / 4.4)$ percent $i$ increased probability of receiving DB. ${ }^{10}$

From the two-stage least squares estimation (row 3) we get that this translates into a 5.1 percentage points increase in disability benefit take-up rates for individuals who would take use of Sassam if being offered early but not if being offered late.

Table 2. Effects on the sickness benefits (SB), unemployment $(\mathrm{U})$ and disability benefits (DB) after 15 months, in February 2009.

\begin{tabular}{lcccc}
\hline & & $\mathrm{SB}$ & $\mathrm{U}$ & $\mathrm{DB}$ \\
& $(1)$ & $(2)$ & $(3)$ & $(4)$ \\
\hline Sassam & & & & \\
First step (effect on treatment) & $0.164^{* * *}$ & - & - & - \\
& $(0.008)$ & & & \\
Reduced form or ITT & - & 0.002 & -0.001 & $0.008^{* *}$ \\
& & $(0.007)$ & $(0.001)$ & $(0.004)$ \\
LATE & - & 0.013 & -0.003 & $0.051^{* *}$ \\
AM & & $(0.044)$ & $(0.035)$ & $(0.022)$ \\
First step (effect on treatment) & $0.044^{* * *}$ & - & & \\
Reduced form or ITT & $(0.011)$ & & & - \\
LATE & - & -0.010 & -0.010 & 0.003 \\
& & $(0.011)$ & $(0.008)$ & $(0.005)$ \\
& - & -0.238 & -0.217 & 0.059 \\
& & $(0.259)$ & $(0.197)$ & $(0.121)$ \\
\hline
\end{tabular}

Notes: Estimation of linear regression models with ordinary least squares (OLS) and two-stage least squares (2SLS) with covariates (gender, age (5 levels), employed/unemployed/other, full time/part time sick reported, daily compensation (4 levels), date of first assessment (three intervals), married, educational level (4 levels), length of current sick-leave period (4 levels), sick-leave history (4 levels), disability benefit history (yes/no), unemployment history (3 levels), region (22 levels).

\footnotetext{
${ }^{9}$ We control for the covariates displayed in Table 1, where we also have added polynomials for the nonqualitative variables (i.e., age and historic number of days in social insurance).

${ }^{10}$ We obtain the same results when estimating the models without control variables. Because of this there is no need to use the nonparametric LATE estimator suggested by Frölich (2007).
} 


\subsection{Dynamics and Residual State}

The effect on DB of being assessed early is large and also surprising. If anything we would have expected the interventions performed by SIA to bring the sick absent individual closer to the labor market rather than the opposite. Since we have detailed data we have the opportunity to not only study the long-run effect but also the dynamics of the treatment effects, and we can also further investigate how the early interventions affect labor supply.

\subsubsection{Dynamics}

In order to study the dynamics of the treatment effects we use the logit regression model and estimate the effect of being prioritized or assessed early on the log odds of being in labor market states, $j, j=$ unemployment, sickness and disability benefits, at the end of month, $m, m=1, \ldots, 15$, after the experiment. By using the logit regression model we can increase the efficiency and remove any potential observed confounding in the estimation by controlling for individual characteristics, $X$. We have, however, also estimated effects without control variables.

Estimations - by maximum likelihood - are done separately for each state and each month between December 2007 and February 2009. That is, we are for each month $m$ and state $j$ estimating the parameters (lowercase) in:

$\log \left\{\mathrm{E}\left(Y_{i m}^{j}\right) /\left(1-\mathrm{E}\left(Y_{i m}^{j}\right)\right\}=a_{m}^{j}+X_{i}^{\prime} b_{m}^{j}+g_{m}^{j} T_{i}\right.$

where $i$ indexes individual and $T_{i}=1$ if being prioritized, and $T_{i}=0$ if not being prioritized.

The effect of being prioritized to either Sassam or AM is analyzed separately. The increased probability (i.e., odds) of being in state $j$ at month $m$ if being prioritized is then obtained as $\exp \left(g_{m}^{j}\right)$.

The results from the analysis together with the mean prevalence for the treated and controls of being in each of the states are displayed in Tables 3 and $4 .{ }^{11}$ Both tables are divided into three panels: The effects on sickness absence are displayed in panels $\mathrm{A}$, the effects on unemployment are displayed in panels $\mathrm{B}$, and finally the effects on receiving DB are displayed in the $\mathrm{C}$ panels. ${ }^{11}$ In the estimations, we control for covariates. The unadjusted results are qualitatively the same and are presented in Table $\mathrm{C} 1$
in Appendix C. 
Table 3 displays the effect of being prioritized to Sassam. From panel A we can see an increased propensity to be sick absent throughout the whole period. During the first 3 months of 2008, the effect is significantly positive. We thus find a lockingin effect early in the follow-up period, and in February (the peak) the odds of being sick absent are about $4(0.628 / 0.604-1)$ percent higher for those prioritized to Sassam.

From panel B we find that the effect on unemployment is somewhat negative in all but 1 month, but the impact is throughout small and nonsignificant. ${ }^{12}$

Turning to the results in panel $\mathrm{C}$, the reported flows to DB are very small in the first few months after screening why the effect from being prioritized to Sassam is imprecisely estimated. From July of 2008 onward, the impact from being prioritized to Sassam is significantly positively associated with receiving DB. The risk of having DB is 14-22 percent higher from July 2008 forward if being prioritized. In the control group the risk of having disability is monotonously increasing from 2.7 percent in July to 4.4 percent in February 2008. The corresponding risk if being prioritized is also monotonously rising from 3.3 percent to 5.2 percent. Note that the difference in prevalence between the treated and controls is 0.8 percentage points, which is the same estimate obtained from the reduced form of estimation displayed in column 3 in Table 2.

The results from being prioritized to AM are displayed in Table 4. The point estimates are generally smaller than those in the Sassam experiment and no significant effects are found in any of the states in any of the months. Comparing the results, this suggests that the meeting with the caseworker screening the working capacity (Sassam) has a larger impact on subsequent outcome than the meeting with the employer (AM). This result could stem from different effects from the two treatments but also simply from the fact that Sassam takes place before AM.

\subsubsection{The Residual State}

One problem interpreting the analyses is that we lack information on the exit state for the sick absent individuals with other exits than unemployment and receiving DB. We term these states the residual state. A most reasonable assumption is that the vast majority of those in the residual state who were employed at the start of the sick spell

\footnotetext{
${ }^{12}$ Unemployment is defined as being registered at the public employment service as a job seeker. This usually involves either being openly unemployed or a participant in a labor market program. A small share could also be working, either temporarily or part time.
} 
returned to work. For the unemployed individuals the situation is different; for them, being in the residual state is perhaps more likely associated with being out of the labor force. Since we have information on yearly income from work in November 2008 we can test for differences in labor force participation among the treated and controls. An individual with a positive labor income in November is assumed to be working.

In November 2008, 54 percent of the employed were in this residuals state. Of these, 98 percent (both the S-treated and S-controls) were working. Among the unemployed, 23 percent were neither reported as sickness or disability benefit recipients, or as unemployed. In this group, 73 percent had a reported income from work in 2008. This indicates that a larger share of the unemployed had left the labor force; however, not ending up in the disability benefit state. Furthermore, the share with a working income is lower among the $\mathrm{S}$-controls (67 percent) compared to the S-treated (80 percent). This suggests that rather than staying on sick leave or receiving $\mathrm{DB}$, the $\mathrm{S}$-controls left the labor force to, for example, collect welfare, be supported by their spouse, or pursue higher education. 
Table 3. Effects (odds ratios) of being prioritized to Sassam and treated and controls prevalence on sickness absence, unemployment, and receiving disability benefit

\begin{tabular}{|c|c|c|c|c|c|c|c|c|c|c|c|c|c|}
\hline & \multicolumn{4}{|c|}{ Sickness absence (A) } & \multicolumn{5}{|c|}{ Unemployment (B) } & \multicolumn{4}{|c|}{ Disability benefit $(C)$} \\
\hline & \multicolumn{2}{|c|}{ Effect } & \multicolumn{2}{|c|}{ Prevalence } & \multicolumn{2}{|l|}{ Effect } & \multicolumn{2}{|c|}{ Prevalence } & \multirow[b]{2}{*}{ Odds } & \multicolumn{2}{|c|}{ Estimate } & \multicolumn{2}{|c|}{ Prevalence } \\
\hline & Odds ratio & St. err & Control & Treated & Odds ratio & St. err & Control & Treated & & ratio & St. err & Control & Treated \\
\hline Dec -07 & 1.031 & $(0.047)$ & 0.827 & 0.834 & 0.939 & $(0.089)$ & 0.047 & 0.043 & & 11.043 & $(1.781)$ & 0.000 & 0.001 \\
\hline Jan -08 & 1.066 & $(0.038)^{*}$ & 0.686 & 0.702 & 0.942 & $(0.070)$ & 0.079 & 0.075 & & 0.628 & $(0.545)$ & 0.001 & 0.001 \\
\hline Feb -08 & 1.098 & $(0.036)^{* * *}$ & 0.604 & 0.628 & 1.018 & $(0.065)$ & 0.092 & 0.092 & & 0.904 & $(0.383)$ & 0.002 & 0.002 \\
\hline Mar -08 & 1.061 & $(0.035)^{*}$ & 0.534 & 0.552 & 0.920 & $(0.063)$ & 0.107 & 0.100 & & 0.974 & $(0.301)$ & 0.003 & 0.004 \\
\hline Apr -08 & 1.016 & $(0.035)$ & 0.491 & 0.498 & 0.955 & $(0.061)$ & 0.113 & 0.108 & & 1.229 & $(0.229)$ & 0.005 & 0.007 \\
\hline May -08 & 1.044 & $(0.035)$ & 0.439 & 0.452 & 0.963 & $(0.060)$ & 0.117 & 0.113 & & 1.130 & $(0.187)$ & 0.008 & 0.010 \\
\hline Jun -08 & 1.060 & $(0.036)$ & 0.387 & 0.403 & 0.960 & $(0.058)$ & 0.124 & 0.120 & & 1.196 & $(0.139)$ & 0.015 & 0.018 \\
\hline Jul -08 & 1.036 & $(0.037)$ & 0.348 & 0.358 & 0.970 & $(0.057)$ & 0.128 & 0.125 & & 1.232 & $(0.105)^{\star *}$ & 0.027 & 0.033 \\
\hline Aug -08 & 1.040 & $(0.037)$ & 0.332 & 0.344 & 0.940 & $(0.057)$ & 0.130 & 0.124 & & 1.217 & $(0.102)^{*}$ & 0.029 & 0.035 \\
\hline Sep -08 & 1.013 & $(0.038)$ & 0.321 & 0.327 & 0.922 & $(0.056)$ & 0.137 & 0.129 & & 1.238 & $(0.099)^{* *}$ & 0.031 & 0.037 \\
\hline Oct -08 & 1.018 & $(0.038)$ & 0.307 & 0.313 & 0.945 & $(0.056)$ & 0.139 & 0.133 & & 1.214 & $(0.096)^{\star *}$ & 0.033 & 0.040 \\
\hline Nov -08 & 1.040 & $(0.038)$ & 0.290 & 0.301 & 0.961 & $(0.055)$ & 0.146 & 0.141 & & 1.188 & $(0.092)^{*}$ & 0.037 & 0.043 \\
\hline Dec -08 & 1.024 & $(0.039)$ & 0.272 & 0.280 & 0.966 & $(0.053)$ & 0.155 & 0.150 & & 1.205 & $(0.090)^{\star *}$ & 0.039 & 0.046 \\
\hline Jan -09 & 1.034 & $(0.040)$ & 0.249 & 0.257 & 0.973 & $(0.052)$ & 0.161 & 0.157 & & 1.180 & $(0.087)^{\star}$ & 0.042 & 0.048 \\
\hline Feb -09 & 1.013 & $(0.041)$ & 0.240 & 0.246 & 0.988 & $(0.052)$ & 0.164 & 0.162 & & 1.222 & $(0.085)^{\star *}$ & 0.044 & 0.052 \\
\hline
\end{tabular}

Notes: Logit regressions with covariates (gender, age (5 levels), employed/unemployed/other, full time/part time sick reported, daily compensation (4 levels), date of first assessment (three intervals), married, educational level (4 levels), length of current sick-leave period (4 levels), sick-leave history (4 levels), disability benefit history (yes/no), unemployment history ( 3 levels), region (22 levels)). Number of observations, Sassam: 13,547.*/**/*** indicates significance at the 10/5/1 percent level. 
Table 4. Effects (odds ratios) of being prioritized to AM and treated and controls prevalence on sickness absence, unemployment, and receiving disability benefit

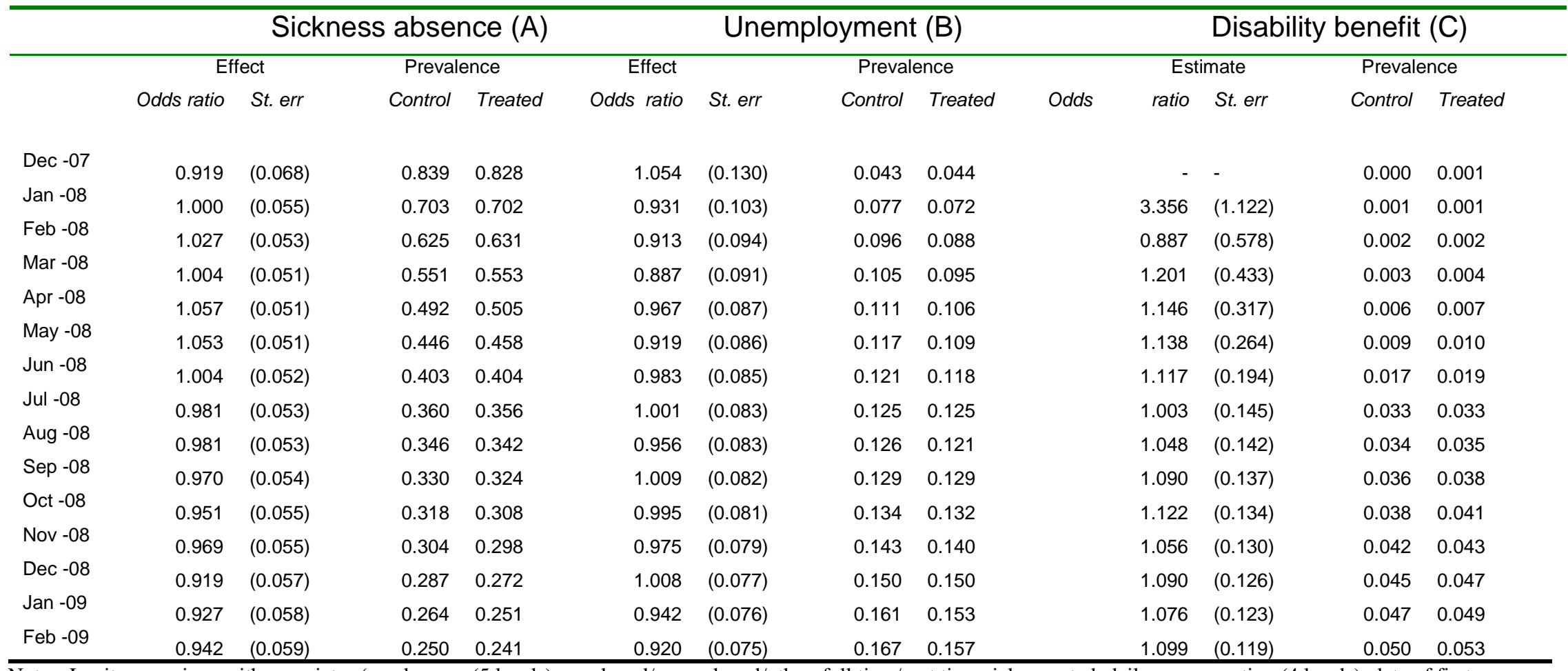

Notes: Logit regressions with covariates (gender, age (5 levels), employed/unemployed/other, full time/part time sick reported, daily compensation (4 levels), date of first assessment (three intervals), married, educational level (4 levels), length of current sick-leave period (4 levels), sick-leave history (4 levels), disability benefit history (yes/no), unemployment history (3 levels), region (22 levels). Number of observations, AM: 6,517. */***** indicates significance at the 10/5/1 percent level. 


\subsection{Robustness Analysis}

We found some mean differences between the S-treated and S-controls in section 3. The S-treated consists of more women, they are younger, and they had more historic sickness absence than the S-controls. Since receiving DB are often foregone by longterm sickness, the effect of being prioritized to Sassam on DB could be biased upward if these differences are not controlled for. From the analysis we could however not find any difference in results when we did not add control variables.

One concern still is that there is some unobserved difference stemming from the initial screening that also is correlated with receiving DB. To test for this possibility we repeat the analysis of the effect on DB by taking use of the individuals flowing into sickness benefits (i.e., longer than 14 days of absence) between 1 September and 30 November 2007. The total population includes all "potentially treated" and consists of 87,136 individuals.

The total population and the experiment populations are very similar with regard to gender, age, and educational level (see Table A1 in appendix A for the total population). The experimental population has as expected more historic sickness absence. The total population is more balanced than the experimental population. However, women are still overrepresented among the S-treated (see Table A1). The reason for this must simply just be accidental.

The results from estimation of the logit regression model (1) are displayed in Table 5. Since only about 15 percent of the total population was included in the experiment, the effects of being prioritized should be considerably attenuated. This result is also confirmed in Table $5 .^{13}$ Although smaller, the effect is positive and significant from September and onward. The results thus strengthen the results obtained in the analysis in section 4.2. In order to get an understanding of these quite counterintuitive results, that is, an increased likelihood of receiving DB when being prioritized to Sassam, we set up a theoretical model in the next section, which is empirically tested in section 6.

\footnotetext{
${ }^{13}$ We have also repeated the analysis with the other outcomes and with AM, but we did not find any significant results.
} 
Table 5. Effects (odds ratios) on disability benefit receipt from being prioritized to Sassam, using the total population

\begin{tabular}{lcc}
\hline & Odds ratio & St. err \\
\hline Dec -07 & 1.208 & $(0.221)$ \\
Jan -08 & 1.067 & $(0.177)$ \\
Feb -08 & 1.183 & $(0.160)$ \\
Mar -08 & 1.163 & $(0.168)$ \\
Apr -08 & 1.115 & $(0.117)$ \\
May -08 & 1.022 & $(0.101)$ \\
Jun -08 & 1.042 & $(0.080)$ \\
Jul -08 & 1.121 & $(0.063)$ \\
Aug -08 & 1.104 & $(0.061)$ \\
Sep -08 & 1.115 & $(0.059)^{\star}$ \\
Oct -08 & 1.106 & $(0.057)^{\star}$ \\
Nov -08 & 1.102 & $(0.055)^{\star}$ \\
Dec -08 & 1.122 & $(0.053)^{\star *}$ \\
Jan -09 & 1.091 & $(0.051)^{\star}$ \\
Feb -09 & 1.105 & $(0.050)^{\star *}$ \\
\hline
\end{tabular}

Notes: Logit regressions with covariates (gender, age (5 levels), employed/ unemployed/other, full time/part time sick reported, daily compensation (4 levels), married, educational level (4 levels), sick-leave history (4 levels), disability benefit history (yes/no), unemployment history (3 levels), region (22 levels). Number of observations: $87,136 . * / * * / * * *$ indicates significance at the $10 / 5 / 1$ percent level.

\section{$5 \quad$ Theoretical Framework}

The purpose of this theoretical section is to show that the empirical patterns we have found may be explained by a simple dynamic model. The basic ideas of the model are the following: (i) we assume that the caseworkers only observe the health signaled by the individuals and not their true health, (ii) conditional on health, wage and benefits, a sick-absent individual chooses a health-signal that maximizes the value of being on sickness benefits, taking into account that the transition rates to work and DB are determined by the signal, (iii) signaling bad health is, however, not without effort. The effort of signaling bad health is assumed to be lower when the working capacity is being assessed by the caseworker. ${ }^{14}$

\footnotetext{
${ }^{14}$ It may seem natural to assume a positive causal link between early interventions and health. However, since this is not consistent with our empirical results we for simplicity take health status as given and focus on the communication between the sick absent individual and their caseworker.
} 


\subsection{The model}

We consider a large number of forward-looking and infinitely lived individuals. All individuals start in the sick absent state $(s)$. They may exit sickness absence and i) go back to work $(e)$, or ii) enter the disability insurance system $(d)$. These last two states are both considered as absorbing. ${ }^{15}$ The individuals differ in health status, $h \in(0, \infty)$. A higher value of $h$ indicates worse health. The instantaneous utility of working is $w-h$, where $w$ is the wage. The health status is arguably of main importance for the instantaneous utility of working. ${ }^{16}$

Health is unobserved by the caseworker. A sick absent individual communicates a health status $(\theta)$ to the caseworker at the SIA. $\theta \in(0, \infty)$ is a continuous individual choice variable where a high value of $\theta$ means a strong signal of health problems. Communicating bad health is associated with instantaneous effort given by $\psi_{T} \theta$, where sub-index $T$ takes value one if an individual has been given priority to interventions (e.g., Sassam) and zero if not. We assume $\psi_{1}<\psi_{0}$, i.e. that the effort of communicating bad health is lower if one belongs to the prioritized group.

The caseworkers base their decisions on the communicated health. The model is thus based on asymmetric information regarding true health status. However, in order to gain analytical tractability we simplify the decisions made by the uninformed part (i.e., the caseworkers). We assume that there is a baseline exogenous exit rate to DB, $\bar{\alpha}_{d}>0$, and a corresponding baseline exit rate to employment $\bar{\alpha}_{e}>0 .{ }^{17}$ The individual exit rate to DB is assumed to be given by $\bar{\alpha}_{d} \theta$, and the corresponding exit rate back to work is assumed to be given by $\bar{\alpha}_{e} / \theta$. Increasing the signal of bad health thus decreases (increases) the exit rate to employment (disability insurance). The sickness benefits $b$ is taken to be lower than the wage, $0<b<w$. Without loss of generality we let the benefit be zero when on $\mathrm{DB}$, which means that the state value of DB is zero $\left(V_{d}=0\right)$.

\footnotetext{
15 The assumption that DB is an absorbing state corresponds well with the fact that very few individuals reenter the workforce after entering the disability insurance system. However, that employment is absorbing is arguably unrealistic. The assumption is made in order to keep the model analytically tractable. A reasonable conjecture is that a more rigorous treatment would change the quantitative, but not qualitative, results of the model.

${ }^{16}$ For our purpose there is no gain in including disutility of bad health in either SB or DB. The key assumption is that an individual suffers more from bad health while working compared to not working. Engström and Holmlund (2007) specify a model with a similar assumption.

${ }^{17}$ The model is set up in continuous time.
} 
The state values while employed $\left(V_{e}(h, w)\right)$ and as sick absent $\left(V_{s}(h, w, \theta)\right)$ are now given as

$$
\delta V_{e}(h, w)=w-h
$$

and

$$
\delta V_{s}(h, w, \theta)=b-\psi_{T} \theta-\bar{\alpha}_{d} \theta V_{s}(h, w, \theta)+\frac{\bar{\alpha}_{s}}{\theta}\left(V_{e}(h, w)-V_{s}(h, w, \theta)\right)
$$

where $\delta>0$ denotes the subjective discount rate.

\subsection{Optimal Choice of Communicated Health}

When characterizing the optimal choice of $\theta$, we treat two types of individuals separately: i) those who weakly prefer work before sickness absence, that is, $V_{e}(h, w)-V_{s}(h, w, \theta) \geq 0$, and ii) those who prefer sickness absence before work, that is, $V_{e}(h, w)-V_{s}(h, w, \theta)<0$. Those who prefer work will set $\theta=0$ and thereby directly flow back to work since $\lim _{\theta \rightarrow 0} \bar{\alpha}_{e} / \theta=\infty$. For those who strictly prefer sickness absence over work we will have an interior solution. It is easily confirmed that the second order condition is satisfied at the optimum when $V_{e}(h, w)-V_{s}(h, w, \theta)<0$ holds. We may therefore rely on the first order condition given by ${ }^{18}$

$$
\delta \frac{\partial V_{s}(h, w, \theta)}{\partial \theta}=-\psi_{T}-\bar{\alpha}_{d} V_{s}(h, w, \theta)-\frac{\bar{\alpha}_{s}}{\theta^{2}}\left(V_{e}(h, w)-V_{s}(h, w, \theta)\right)=0
$$

Solving for $V_{e}(h, w)$ and $V_{s}(h, w, \theta)$ from equations (2) and (3) and combining with equation (4) gives an equation that determines $\theta\left(h, w ; \psi_{T}\right)$, that is, the optimal level of communicated health. However, in order to derive the comparative statics it is more convenient to use equation (4) directly by making use of the envelope property. Differentiation of equation (4) with respect to $\theta$ and $h$ gives

$$
\theta_{h}^{\prime}(h, w)=\frac{\frac{\bar{\alpha}_{w}}{\theta^{2}}-\frac{\partial\left(V_{e}(h, w)-V_{s}(h, w, \theta)\right)}{\partial h}+\bar{\alpha}_{d}-\frac{\partial V_{s}(h, w, \theta)}{\partial h}}{2 \frac{\bar{\alpha}_{w}}{\theta^{3}}\left(V_{e}(h, w)-V_{s}(h, w, \theta)\right)}>0 .
$$

\footnotetext{
${ }^{18}$ Note that the optimal choice of $\theta$ will not change over time. It is therefore irrelevant whether the individual reevaluates the choice of $\theta$ tomorrow or not. Technically, the indirect effect of $\theta$, on the right hand side, will be zero due to the envelope property.
} 
This result is obtained since $\partial\left(V_{e}(h, w)-V_{s}(h, w, \theta)\right) / \partial h<0$ and $\partial V_{s}(h, w, \theta) / \partial h<0$ which is obtained directly from differentiating equations (2) and (3), and $V_{e}(h, w)-V_{s}(h, w, \theta)<0$ is implied by the preference assumption. The result states that the more you suffer from bad health (holding wage constant) while working, the more bad health you will communicate in order to avoid being sent back to work.

Turning to the effect of early interventions, differentiation of equation (4) with respect to $\theta$ and $\psi_{T}$ gives

$$
\theta_{\psi_{T}}^{\prime}(h, w)=\frac{\frac{\delta+2 \frac{\bar{\alpha}_{e}}{\theta}}{\delta+\bar{\alpha}_{d} \theta+\frac{\bar{\alpha}_{e}}{\theta}}}{2 \frac{\bar{\alpha}_{e}}{\theta^{3}}\left(V_{e}(h, w)-V_{s}(h, w, \theta)\right)}<0
$$

This result also stems directly from differencing equations (2) and (3) and from the preference assumption. Thus, for all individuals who prefer sickness absence before work we get the result that treatment, which we assume is captured by a decrease in $\psi_{T}$, will increase the level of bad health communicated to the SIA.

If individuals only differ in health status the moral hazard properties of the model are not apparent - the probability of entering DB (exiting to work) is increasing (decreasing) in the true level of bad health. But when also introducing wage heterogeneity the moral hazard involved is made clearer. The comparative statics for wage are easily determined. Consider instead the effects of changing the wage level while holding health status constant. The structure of the model implies that $\theta_{h}^{\prime}(h, w)=-\theta_{w}^{\prime}(h, w)$, which means that increased pecuniary incentive to return to work mirrors the effect of better health. ${ }^{19}$ The theoretical implication of having worse health is therefore the same as the effect of having a lower wage. This means that an individual who communicates bad health could be relatively healthy if he suffers from low pecuniary incentives to return to work. The model could easily be extended to more subjective factors influencing the incentives to return to work, such as social work norms and other subjective rewards of being in work compared to sick leave (and DB). Heterogeneity in any other dimension related to work incentives will cause

\footnotetext{
${ }^{19}$ In reality the Swedish sickness benefits can be characterized by $b=\min (\rho w, \bar{b})$, where $\rho$ denotes the replacement rate below the cap $\bar{b}$. Our model with exogenous benefit level thus corresponds to the case above the cap, which arguably overstates the average pecuniary incentive to return to work due to a wage increase.
} 
moral hazard, provided that the social objective is only to insure against bad health chocks.

\subsection{A Numerical Example}

By choosing specific model parameters we can give a numerical illustration of the flows, month by month, and facilitate qualitative comparisons between model and data. The results from this numerical example are displayed in Figures 4 and 5 .

We normalize the wage to unity and let the health measure be uniformly distributed between zero and 1.5 , that is, $w=1$ and $h \sim U(0,1.5)$. The sickness benefit is set to 0.5 . The monthly baseline outflow rates are given by $\bar{\alpha}_{d}=0.01$ and $\bar{\alpha}_{e}=0.1$. We capture the effect of being (randomly) prioritized to early interventions with a decrease in $\psi_{T}$ from its baseline level, $\psi_{0}=0.2$ (control), to $\psi_{1}=0.15$ (treatment). We let the size of the treatment and control group be normalized to 1 . We think of these groups as very large and abstract from aggregate uncertainty. Finally, we set the monthly subjective discount rate to $\delta=0.01$.

Figure 4 graphs the relative risk, or odds ratios, for the treated compared to controls in each state for each month from December 2007 to January 2008. From this figure we can clearly see the locking-in effect of the intervention. The treated have initially a higher risk of being sick in February. The relative risk is approximately 2 percent higher for the treated compared to the controls. Thereafter the relative odds are decreasing. The pattern of the relative risk of SB is explained by the relative sizes of the total exit rate from SB. In the beginning, when average health is relatively high, the control's exit rate is higher due to high exit back to work. Later on, however, when average health is low, the treated exit relatively fast due to higher exit rate to DB. The pattern of the relative risk of being in DB is due to a direct treatment effect and dynamic selection. At the beginning the treated exit is faster to DB since their cost of communicating bad health is lower. However, as time passes the number of individuals with bad health will be higher in the control group, which explains the downward sloping odds ratio for DB.

The general result of an increased risk of around 20 percent for the treated of taking DB is in line with the empirical results. However, the time pattern, with an almost immediate higher likelihood of receiving DB, is not what we find in the data. This result stems from the simplifying assumption that an individual who communicates 
bad health (i.e., high $\theta$ ) will immediately get a higher probability to enter into DB. In real life the decision to receive DB takes some time. For example, in our data no individual receives DB during the second month (see Table 3).

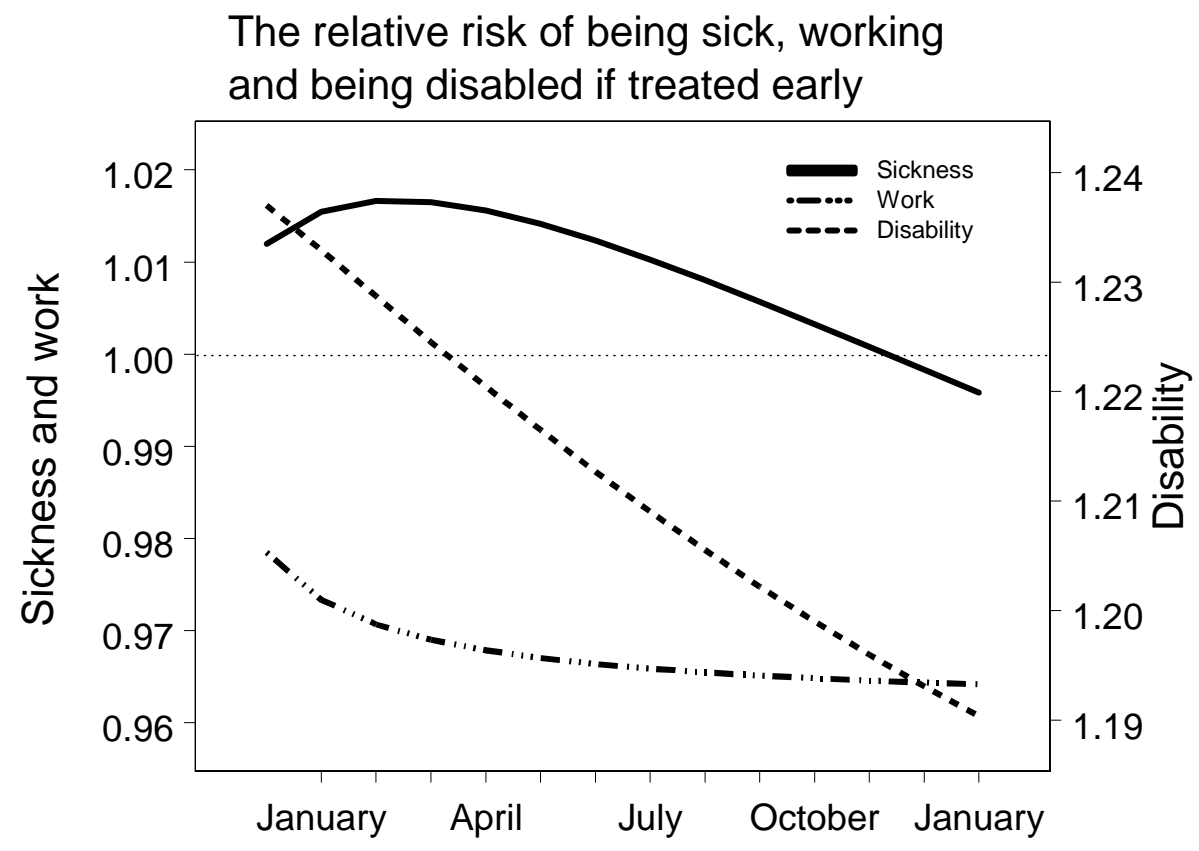

Figure 4. The relative risk or odds ratio (treated/controls) of being in each state, SB, Work, or DB

Figure 5 shows the difference between treatment and control group probabilities of receiving DB for different levels of (un)health. For individuals with good health (low $h)$ the difference is very small. For individuals with less good health the effect of treatment is more important. As our model setup is symmetric with respect to pecuniary incentives and health, the theoretical implication of being unhealthy is the same as the effect of having low costs of receiving DB. This implies that increased access to early interventions will be more important for individuals with lower incentives to return to work (low cost or bad health). The benefits in the Sickness insurance are typically higher than the benefits in unemployment insurance (see section 2). This implies that most unemployed have economic incentives to become and also stay sick. It is also highly likely that the unemployed individuals have worse health than employed individuals. The implication from our model is then that as the unemployed have larger incentives to communicate bad health the treatment effects would be larger for them than for employed individuals. Since we have information 
on individual employment status we have an empirically testable result that we will address in the next section.

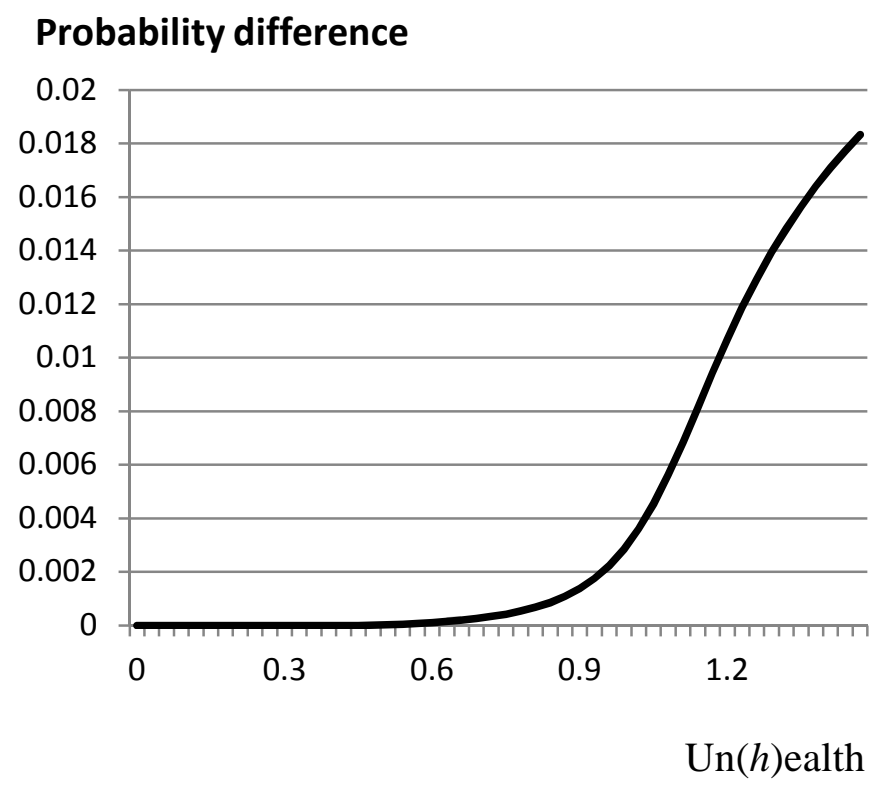

Figure 5. Treatment to control differences in monthly outflow probabilities $\left(1-e^{-\bar{\alpha}_{d} \theta}\right)$ to receive DB.

\section{$6 \quad$ Effects for Unemployed and Employed}

We repeat the above analysis in the Sassam experiment for each month and state, now separately for the employed and unemployed.

In Panel A of Table 6 we display the effects on sickness absence. From this panel we can see large differences in effects between the two groups. For the employed we find evidence of locking in effects in February 2008, but from March the effect is basically zero. For the unemployed, the locking-in effect is larger but the effect is also high and statistically significant until November. The relative risk of being sick absent if prioritized is 37 percent higher in March than if not prioritized (53 percent of the controls are on sickness benefits). In October the corresponding risk is 27 percent (35 percent of the controls are on sickness benefits).

There are no statistically significant effects on unemployment among the employed (Panel B). The point estimates are in general lower for unemployed, and for this group we also have weakly statistically significant effects in some months. From panel C we can see increasing risk of getting DB if being prioritized to Sassam for both employed and unemployed. The effects are statistically significant from June and forward. After the first 6 months, the impact is generally about twice as 
large for the unemployed as for the employed. For example, the uptake in June for the unemployed controls is 3 percent compared with 1.5 percent among the employed controls. In February 2009, the corresponding figures are 7.5 percent and 4 percent. This means that the differences in effects are also highly economically relevant. Being prioritized to Sassam would increase the likelihood of having DB from 7.5 percent to 10.6 percent 15 months later. The corresponding figure for the employed is an increase from 4 percent to 5 percent.

The result from this analysis supports the hypothesis that the effect observed in section 4 can stem from the lower cost of communicating or signaling health problems when being assessed in a Sassam meeting. Parsons (1978) suggests that rehabilitation initiatives among the sick absent individuals could create or magnify a "sickness identity" of individuals making use of sickness or disability insurance. This could then lead to an increased take-up of sickness and disability benefits, instead of decreased. If unemployed individuals in comparison with the employed are more likely to get a sickness identity when being assessed or exposed to an intervention, this would generate the same pattern as observed in our data, and then the suggested analysis cannot discriminate between the two theories. 
Table 6. Effect from Sassam on the probability of sickness-absence, unemployment, and receiving disability benefit, for employed and unemployed

\begin{tabular}{|c|c|c|c|c|c|c|c|c|c|c|c|c|}
\hline & \multicolumn{4}{|c|}{ Sickness absence $(A)$} & \multicolumn{4}{|c|}{ Unemployment (B) } & \multicolumn{4}{|c|}{ Disability benefit (C) } \\
\hline & \multicolumn{2}{|c|}{ Employed } & \multicolumn{2}{|c|}{ Unemployed } & \multicolumn{2}{|c|}{ Employed } & \multicolumn{2}{|c|}{ Unemployed } & \multicolumn{2}{|c|}{ Employed } & \multicolumn{2}{|c|}{ Unemployed } \\
\hline & $\begin{array}{r}\text { Odds } \\
\text { ratio }\end{array}$ & St. err & $\begin{array}{c}\text { Odds } \\
\text { ratio }\end{array}$ & St. err & $\begin{array}{c}\text { Odds } \\
\text { ratio }\end{array}$ & St. err & $\begin{array}{c}\text { Odds } \\
\text { ratio }\end{array}$ & St. err & $\begin{array}{r}\text { Odds } \\
\text { ratio }\end{array}$ & St. err & $\begin{array}{l}\text { Odds } \\
\text { ratio }\end{array}$ & St. err \\
\hline Dec - 07 & 1.020 & $(0.053)$ & 1.151 & $(0.138)$ & 1.068 & $(0.125)$ & 0.857 & $(0.136)$ & 11.043 & $(1.781)$ & - & - \\
\hline Jan -08 & 1.038 & $(0.042)$ & 1.193 & $(0.115)$ & 1.000 & $(0.093)$ & 0.931 & $(0.116)$ & 3.752 & $(1.091)$ & - & - \\
\hline Feb -08 & 1.084 & $(0.040)^{\star *}$ & 1.142 & $(0.110)$ & 1.047 & $(0.085)$ & 1.048 & $(0.112)$ & 2.634 & $(0.577)$ & 0.351 & $(1.112)$ \\
\hline Mar -08 & 1.023 & $(0.039)$ & 1.370 & $(0.108)^{\star \star \star}$ & 1.018 & $(0.081)$ & 0.846 & $(0.109)$ & 1.503 & $(0.421)$ & 0.611 & $(0.703)$ \\
\hline Apr -08 & 0.992 & $(0.039)$ & 1.203 & $(0.108)^{*}$ & 1.016 & $(0.077)$ & 0.885 & $(0.109)$ & 1.470 & $(0.297)$ & 1.223 & $(0.465)$ \\
\hline May -08 & 1.015 & $(0.039)$ & 1.267 & $(0.108)^{\star \star}$ & 1.052 & $(0.076)$ & 0.835 & $(0.108)^{\star}$ & 1.294 & $(0.229)$ & 1.076 & $(0.393)$ \\
\hline Jun -08 & 1.039 & $(0.040)$ & 1.246 & $(0.108)^{\star \star}$ & 1.023 & $(0.073)$ & 0.904 & $(0.107)$ & 1.291 & $(0.170)$ & 1.568 & $(0.292)$ \\
\hline Jul -08 & 1.012 & $(0.041)$ & 1.188 & $(0.109)$ & 1.051 & $(0.071)$ & 0.886 & $(0.107)$ & 1.223 & $(0.123)^{\star}$ & 1.765 & $(0.236)^{* *}$ \\
\hline Aug -08 & 1.019 & $(0.041)$ & 1.217 & $(0.109)^{*}$ & 1.028 & $(0.071)$ & 0.824 & $(0.107)^{*}$ & 1.224 & $(0.120)^{*}$ & 1.686 & $(0.228)^{* *}$ \\
\hline Sep -08 & 0.982 & $(0.042)$ & 1.208 & $(0.111)^{*}$ & 1.003 & $(0.069)$ & 0.818 & $(0.107)^{*}$ & 1.267 & $(0.116)^{\star \star}$ & 1.562 & $(0.219)^{\star *}$ \\
\hline Oct -08 & 0.987 & $(0.042)$ & 1.270 & $(0.111)^{\star \star}$ & 1.033 & $(0.068)$ & 0.826 & $(0.108)^{*}$ & 1.232 & $(0.112)^{*}$ & 1.502 & $(0.215)^{*}$ \\
\hline Nov -08 & 1.023 & $(0.043)$ & 1.171 & $(0.112)$ & 1.007 & $(0.066)$ & 0.912 & $(0.108)$ & 1.207 & $(0.108)^{*}$ & 1.500 & $(0.208)^{*}$ \\
\hline Dec -08 & 1.011 & $(0.044)$ & 1.184 & $(0.113)$ & 1.012 & $(0.065)$ & 0.913 & $(0.107)$ & 1.244 & $(0.105)^{\star \star}$ & 1.406 & $(0.201)^{*}$ \\
\hline Jan -09 & 1.027 & $(0.045)$ & 1.162 & $(0.114)$ & 1.005 & $(0.063)$ & 0.959 & $(0.108)$ & 1.197 & $(0.102)^{\star}$ & 1.390 & $(0.198)^{\star}$ \\
\hline Feb -09 & 1.009 & $(0.046)$ & 1.103 & $(0.115)$ & 1.019 & $(0.062)$ & 0.975 & $(0.107)$ & 1.253 & $(0.099)^{\star \star}$ & 1.412 & $(0.193)^{*}$ \\
\hline
\end{tabular}

Notes: Logit regressions with covariates (gender, age (5 levels), full time/part time sick reported, daily compensation (4 levels), date of first assessment (three intervals),

married, educational level (4 levels), length of current sick-leave period (4 levels), sick-leave history (4 levels), disability benefit history (yes/no), unemployment history (3 levels), region (22 levels). Number of observation, employed: 11,077, unemployed: 1,561. */**/*** indicates significance at the 10/5/1 percent level. 


\section{Conclusion}

This paper studies the effects of two types of early interventions taken by the Swedish Social Insurance Agency (SIA) on individuals with sickness benefits. The first, Sassam, screens the working capacity of the individual and the need for vocational rehabilitation. The second, AM, is a formalized meeting between the sick absent individual, the SIA, and the employer where the possibility to return to alternative work tasks are discussed and appropriate vocational rehabilitation measures are decided upon.

We take use of a large randomized social experiment conducted in collaboration with the SIA in 2007. In the experiment, individuals were randomly chosen from the inflow of sickness benefits to be given priority to Sassam and AM during a 6-week period. Individuals of the randomly chosen control group were not prioritized to these activities during the same 6 weeks, but could be offered the same activities after the 6 weeks. The implication of the evaluation design is that the probability of having Sassam and AM early should be higher in the treatment (prioritized) group, compared to the control group. This is also found in data: those given priority are found to have a 16.4 and 4.4 percentage point increased likelihood of receiving Sassam and AM, respectively.

We estimate effects on the prevalence in three states for 15 months after the experiment was conducted (December 2007 to February 2009). The three nonexclusive - states are whether one is i) receiving sickness benefits, ii) unemployed, or iii) receiving disability benefits (DB).

We find evidence of locking-in effects in sickness absence of being prioritized to Sassam. Furthermore, we find an around 20 percent increase in the take-up rate of DB from being prioritized to Sassam 7 to 15 months after the experiment was conducted. This corresponds to a 5.1 percent increased likelihood of having disability befits when exposed to Sassam early. We find no statistically significant effects from being prioritized to AM.

The result of an increasing likelihood of receiving both sickness and DB when being given priority to the Sassam is surprising. If anything we expected the interventions performed by SIA to bring the sick absent individual closer to the labor market rather than the opposite. The reason for this prior was that, despite basically 
no evidence of positive effects from vocational rehabilitations of sick absent, ${ }^{20}$ there is by now evidence of threat effects also ${ }^{21}$ in the sickness insurance (cf. Hesselius et al., 2005; Hägglund, 2010; Johansson and Lindahl, forthcoming; de Jong et al., 2011). That is, an increased hazard from sickness absence when individuals are monitored and before entering rehabilitation schemes. ${ }^{22}$ de Jong et al. (2011) also find a reduction in applications to DB.

To further our understanding we formulate a theoretical model in section 5. In this model sick absent individuals may want to receive DB (secure payment and no work). In order to get DB an individual communicates or signals health problems when being sick absent. There is, however, a cost of signaling, and this cost is reduced if the individual is being assessed by the SIA. The implication is hence that the treated individuals who prefer work absence in front of work remain sick absent longer and then obtain DB to a higher degree than those not assessed. The model also predicts that the effect from being assessed should be larger for those with bad health and for those with low costs of being work absent (or low incentives to resume from work absence). This hypothesis is then tested in section 6 , where we estimate the effects separately for unemployed (low incentives to resume and/or bad health) and employed. We find that the effects on sickness and disability benefits are larger for unemployed than for those who are employed at the start of their sickness absence spell, which was expected from our theoretical framework. This, hence, does not reject our hypothesis of a signaling effect.

In the literature it has been hypothesized (e.g., Parsons, 1978) that rehabilitation could give the sick absent individual an identity as being ill, which then will cause longer and/or more sickness absence. Based on Swedish data, Andersén et al. (2008) also found that active rehabilitation could prolong, rather than shorten, sickness absence, which hence supports this theory. The theory discussed above would be an alternative. If the unemployed individuals are more likely to in comparison with the employed define themselves as ill when being assessed and/or exposed to vocational rehabilitation then the two theories cannot be tested using the analysis performed

\footnotetext{
${ }^{20}$ See, e.g., Elders et al. (2000), Bloch and Prins (2001), Alexandersson and Nordlund (2004), Andrén and Palmer (2004), Blank et al. (2008), Försäkringskassan (2007), and van Oostrom et al. (2009, 2010).

${ }^{21}$ In the unemployment insurance literature there is, by now, plenty of evidence of increased exit rates from the unemployment insurance before monitoring and screening and program start (see, e.g., Black et al. (2003), Geerdsen (2006), Geerdsen and Holm (2007), Rosholm and Svarer (2008), Graversen and Van Ours (2008), Arni et al. (2009), and Hägglund (2011)). These effects are known as threat and pre-program (or pre-treatment) effects in this literature.

${ }^{22}$ Somewhat related, Borghans et al. (2010) find that an increased stringency in the Dutch disability insurance increased the outflow from disability insurance to social assistance.
} 
here. The theoretical framework is to some extent related, or rather the opposite, to the self-screening model suggested by Parsons (1991). In this model long waiting times to decision will lead to fewer claims of DB. The reason for this is that there is uncertainty of a decision from a claim and there is cost of waiting and not working if the claims are not granted. Furthermore, if the time preferences for individuals with good and bad health are the same, the cost of waiting for those with good health is larger than for those with bad health.

The main policy lesson learned from this study is that if interest is in reducing the inflow to DB for individuals with a capacity to work, the screening and monitoring of eligibility for DB should be taken in isolation from the process of assessing individuals' needs of vocational rehabilitation. Hence, the suggestion by Autor and Duggan (2010) of increasing employer responsibility and early intervention at the workplace together with an independent screening by, e.g., the SIA of eligibility of DB could be useful measures in reducing the inflow to DB, at least in Sweden. 


\section{References}

Alexandersson, K. \& Nordlund, A. (2004) Sickness absence - causes, consequences, and physicians'sickness certification practice. A systematic literature review by the Swedish Council on Technology Assessment in Health Care. Chapter 1. Aim, background, key concepts, regulations, and current statistics. Scandinavian Journal of Public Health, 32, 12-30.

Andrén, D. \& Palmer, E. (2004) Deltidssjukskrivning. Working Paper, Försäkringskassan.

Arni, P., R. Lalive and J.C. van Ours (2009). How Effective are Unemployment Benefit Sanctions? CEPR Discussion Papers 7541.

Autor, D. H. \& Duggan, M. G. (2010). Supporting Work: A Proposal for Modernizing the U.S. Disability Insurance System. Center for American Progress and the Hamilton Project.

Black, Dan A., Smith, J. A., Berger, M. C. \& Noel, B. J. (2003). Is the threat of reemployment services more effective than the services themselves? Evidence from random assignment in the UI system. American Economic Review, 93(4), 1313-1327.

Blank, L., Peters, J., Pickvance, S., Wilford, J., \& Macdonald, E. (2008). A systematic review of the factors which predict return to work for people suffering episodes of poor mental health. Journal of Occupational Rehabilitation, 18(1): 27-34, Epub 2008, Jan 23, Review.

Bloch Franc, S. \& Prins, R. (red.) (2001). Who Returns to Work \& Why. New Jersey, Transaction Publishers.

Borghans, L., Gielen, A. C., \& Luttmer, E. F. P. (2010). Social Support Shopping: Evidence from a Regression Discontinuity in Disability Insurance Reform. IZA DP 5412.

de Jong, P., Lindeboom, M. \& van der Klaauw, B. (2011). Screening disability insurance applications. Journal of the European Economic Association, 9, 106129.

Elders, L. A., van der Beek, A. J. \& Burdorf, A. (2000). Return to work after sickness absence due to back disorders - a systematic review on intervention strategies. International Archives of Occupational and Environmental Health, 73(5), 339-348.

Engström, P., Goine, H., Johansson, P., Palmer, E. \& Tollin, P. (2010). Underlättar tidiga insatser i sjukskrivningsprocessen återgången i arbete? Rapport, 2010, 11: IFAU.

Engström, P., B. Holmlund (2007). Worker Absenteeism in Search Equilibrium. Scandinavian Journal of Economics, vol. 109(3), pp. 439-467, September 2007.

Frölich, M. (2007). Nonparametric IV estimation of local average treatment effects with covariates. Journal of Econometrics, 139, 35-75.

Försäkringskassan (2010). Tidiga insatser i sjukfallen - vad leder de till? Försäkringskassan, 2010, 8.

Försäkringskassan (2007). Nej till sjukpenning, vad hände sen? (No to sickness benefits, what happened then?). Försäkringskassan, 2007:1.

Geerdsen, L. P. (2006). Is there a threat effect of labor market programmes? A study of ALMP in the Danish UI system. Economic Journal, 116, 738-750.

Geerdsen, L. P., \& Holm, A. (2007). Duration of UI periods and the perceived threat effect from labour market programmes. Labour Economics, 14(3), June, 639-652. 
Graversen, B. \& Van Ours, J. (2008). How to help unemployed find jobs quickly; experimental evidence from a mandatory activation program. Journal of Public Economics, 92 (10-11), 2020-2035.

Hägglund, P. (2011). Are there pre-programme effects of Swedish active labour market policies? Evidence from three randomised experiments. Economics Letters, 112(1), 91-93.

Hägglund, P. (2010). Do Time Limits in the Sickness Insurance System Increase Return to Work? Working Paper 2010, 1: IFAU.

Hesselius, P., Johansson, P. and Larsson, L. (2005). Monitoring Sickness Insurance Claimants: Evidence from a Social Experiment. IFAU Working Paper, 2005, 15.

Imbens, G. \& Angrist, J. (1994). Estimation of local average treatment effects. Econometrica, 62(2), 467-475.

Johansson, P. \& Lindahl, E. (forthcoming). Can sickness absence be affected by information meetings? Evidence from a social experiment. Empirical Economics.

OECD (2009). Sickness, Disability and Work: Breaking the Barriers - Sweden: Will the Recent Reforms Make It? Rapport. OECD.

Parsons, D. (1991). Self-screening in targeted public transfer programs. The Journal of Political Economy, 99, 859-876.

Parsons, T. (1978). The Action Theory and the Human Conditions. New York, Free Press.

Rosholm, M. \& Svarer, M. (2008). The threat effect of active labour market programmes. Scandinavian Journal of Economics, 110, 385-401.

Sjögren Lindquist och Wadensjö (2007). Ett Svårlagt Pussel - Kompletterande Ersättningar Vid Inkomstbortfall. ESS-rapport, 2007, 1.

Sjögren Lindquist, G. \& Wadensjö, E. (2006). Kompletterande ersättningar vid inkomstbortfall och arbetslinjen. In: Olofsson, J. \& Zavisic, M. (eds.) Vägar till en öppnare arbetsmarknad. Arbetslivsinstitutets årsbok, 2006, 124-130.

van Oostrom, S. H., Driessen, M. T., de Vet, H. C., Franche, R. L., Schonstein, E., Loisel, P., van Mechelen, W. \& Anema, J. R. (2009). Workplace interventions for preventing work disability. Cochrane Database System Review, Apr 15(2).

van Oostrom, S. H., Mechelen, W., Berend, T., de Vet, H. C. W., Knol, D. L. \& Anema, J. R. (2010). A workplace intervention for sick-listed employees with distress: Results of a randomised controlled trial. 


\section{Appendix A}

\section{Total population}

Table A1. Descriptives for the total population (all spells initiated 1 September - 30 November 2007), averages

\begin{tabular}{|c|c|c|c|c|c|c|}
\hline & S-treated & S-control & t-test & A-treated & A-control & t-test \\
\hline Women & 0.61 & 0.61 & 2.37 & 0.61 & 0.61 & -0.68 \\
\hline \multirow[t]{2}{*}{ Age } & 46.3 & 46.5 & -1.94 & 46.4 & 46.2 & 2.26 \\
\hline & $(0.06)$ & $(0.06)$ & & $(0.08)$ & $(0.08)$ & \\
\hline Compulsory & 0.17 & 0.17 & -0.98 & 0.17 & 0.16 & 1.53 \\
\hline Upper secondary & 0.54 & 0.54 & 0.98 & 0.54 & 0.54 & -0.71 \\
\hline University & 0.29 & 0.29 & -0.26 & 0.29 & 0.29 & -0.54 \\
\hline $\begin{array}{l}\text { Sick-leave history } \\
\text { (days) }^{a}\end{array}$ & $\begin{array}{c}150 \\
(1.30)\end{array}$ & $\begin{array}{c}149 \\
(1.27)\end{array}$ & 0.27 & $\begin{array}{c}151 \\
(1.86)\end{array}$ & $\begin{array}{c}149 \\
(1.81)\end{array}$ & 0.62 \\
\hline $\begin{array}{l}\text { Unemployment } \\
\text { history (days) }\end{array}$ & $\begin{array}{c}450 \\
(3.37)\end{array}$ & $\begin{array}{c}451 \\
(3.29)\end{array}$ & -0.15 & $\begin{array}{c}448 \\
(4.77)\end{array}$ & $\begin{array}{c}452 \\
(4.76)\end{array}$ & -0.66 \\
\hline $\begin{array}{l}\text { Disability benefit } \\
\text { history (days) }\end{array}$ & $\begin{array}{c}0.51 \\
(0.00)\end{array}$ & $\begin{array}{c}0.51 \\
(0.00)\end{array}$ & 0.31 & $\begin{array}{c}0.51 \\
(0.00)\end{array}$ & $\begin{array}{c}0.51 \\
(0.00)\end{array}$ & -0.41 \\
\hline Unemployed & 0.09 & 0.09 & 1.25 & 0.09 & 0.09 & -0.05 \\
\hline Sassam $^{d}$ & 0.17 & 0.14 & 10.67 & 0.17 & 0.16 & 2.77 \\
\hline $\mathrm{AM}^{\mathrm{d}}$ & 0.13 & 0.12 & 3.84 & 0.13 & 0.12 & 2.89 \\
\hline Share & & 0.486 & & & 0.495 & \\
\hline $\mathrm{N}$ & 42,370 & 44,766 & & 20,987 & 21,383 & \\
\hline
\end{tabular}

Note: ${ }^{a}$ Net days since $1995 .{ }^{b}$ Gross days from 2000. ${ }^{\mathrm{c}}$ Net days since $1995 .{ }^{\mathrm{d}}$ Does not include information from Skåne and Västra Götaland, the averages are thus based on other regions (N=61,222 in the Sassam experiment and $\mathrm{N}=29,755$ in the AM experiment). 


\section{Appendix B}

\section{The Dynamics of Treatment}

Table B1 reports the share of treated and controls in the respective experiment who had received treatment at different occasions. In the Sassam experiment, a large difference between S-treated and S-controls appears immediately after the screening. The treatment difference diminishes with duration but is still substantial in February 2009, 45 percent (0.45-0.31). Compared to the Sassam experiment, the share of treated in the AM experiment is smaller in the first few months after the screening. This is expected since AM followed participation in Sassam. Also, since individuals continuously return to work, the share of treated was smaller compared to the Sassam experiment. The treatment difference was also smaller; in February 2009 the effect on treatment of being prioritized was 15 percent $(0.30-0.26)$. 
Table B1. Share of treated and controls who had received Sassam and AM at different occasions

\begin{tabular}{|c|c|c|c|c|c|c|}
\hline & \multicolumn{3}{|c|}{ Sassam } & \multicolumn{3}{|c|}{ AM } \\
\hline & S-treated & S-control & $\begin{array}{l}\text { Diff. \% } \\
\text { points }\end{array}$ & A-treated & A-control & $\begin{array}{l}\text { Diff. \% } \\
\text { points }\end{array}$ \\
\hline Dec -07 & 0.26 & 0.04 & $\begin{array}{c}0.219^{* * *} \\
(0.007)\end{array}$ & 0.06 & 0.04 & $\begin{array}{l}0.016^{* *} \\
(0.006)\end{array}$ \\
\hline Jan -08 & 0.37 & 0.16 & $\begin{array}{c}0.211^{* * *} \\
(0.009)\end{array}$ & 0.11 & 0.08 & $\begin{array}{c}0.026^{\star * *} \\
(0.009)\end{array}$ \\
\hline Feb -08 & 0.39 & 0.22 & $\begin{array}{c}0.176^{* * *} \\
(0.009)\end{array}$ & 0.14 & 0.10 & $\begin{array}{c}0.037^{* * *} \\
(0.010)\end{array}$ \\
\hline Mar -08 & 0.40 & 0.24 & $\begin{array}{c}0.165^{\star * *} \\
(0.010)\end{array}$ & 0.16 & 0.12 & $\begin{array}{c}0.039^{* * *} \\
(0.010)\end{array}$ \\
\hline Apr -08 & 0.41 & 0.26 & $\begin{array}{c}0.155^{\star * *} \\
(0.010)\end{array}$ & 0.17 & 0.14 & $\begin{array}{c}0.037^{* * *} \\
(0.011)\end{array}$ \\
\hline May -08 & 0.42 & 0.27 & $\begin{array}{c}0.150^{* * *} \\
(0.010)\end{array}$ & 0.19 & 0.15 & $\begin{array}{c}0.042^{* * *} \\
(0.011)\end{array}$ \\
\hline Jun -08 & 0.42 & 0.27 & $\begin{array}{c}0.149^{* * *} \\
(0.010)\end{array}$ & 0.20 & 0.16 & $\begin{array}{c}0.041^{\star * *} \\
(0.012)\end{array}$ \\
\hline Jul -08 & 0.42 & 0.28 & $\begin{array}{c}0.147^{\star * *} \\
(0.010)\end{array}$ & 0.20 & 0.16 & $\begin{array}{c}0.043^{\star * *} \\
(0.012)\end{array}$ \\
\hline Aug -08 & 0.43 & 0.27 & $\begin{array}{c}0.146^{* * *} \\
(0.010)\end{array}$ & 0.21 & 0.17 & $\begin{array}{c}0.042^{* * *} \\
(0.012)\end{array}$ \\
\hline Sep -08 & 0.43 & 0.29 & $\begin{array}{c}0.144^{\star * *} \\
(0.010)\end{array}$ & 0.23 & 0.18 & $\begin{array}{c}0.043^{* * *} \\
(0.012)\end{array}$ \\
\hline Oct -08 & 0.44 & 0.29 & $\begin{array}{c}0.142^{* * *} \\
(0.010)\end{array}$ & 0.24 & 0.19 & $\begin{array}{c}0.045^{\star * *} \\
(0.012)\end{array}$ \\
\hline Nov -08 & 0.44 & 0.30 & $\begin{array}{c}0.142^{* * *} \\
(0.010)\end{array}$ & 0.25 & 0.21 & $\begin{array}{c}0.043^{* * *} \\
(0.013)\end{array}$ \\
\hline Dec -08 & 0.44 & 0.30 & $\begin{array}{c}0.143^{* * *} \\
(0.010)\end{array}$ & 0.26 & 0.23 & $\begin{array}{c}0.033^{* * *} \\
(0.13)\end{array}$ \\
\hline Jan -09 & 0.45 & 0.31 & $\begin{array}{c}0.141^{* * *} \\
(0.010)\end{array}$ & 0.28 & 0.24 & $\begin{array}{c}0.037^{* * *} \\
(0.013)\end{array}$ \\
\hline Feb -09 & 0.45 & 0.31 & $\begin{array}{c}0.141^{* * *} \\
(0.010)\end{array}$ & 0.30 & 0.26 & $\begin{array}{c}0.036^{\star * *} \\
(0.013)\end{array}$ \\
\hline
\end{tabular}

Notes: Standard errors are given within parentheses. T-tests have been performed to test mean differences between the two groups. Number of observations, S-treated: 4,467, S-controls: 4,791, A-treated: 2,208, A-controls: 2,259. Data lack information from Skåne and Västra Götaland. */**/*** indicates significance at the 10/5/1 percent level. 


\section{Appendix C}

Estimation Results without Covariates 
Work in progress - do not quote

Table C1. Effect from Sassam and AM on the probability of sickness-absence, unemployment, and receiving disability benefit, for employed and unemployed. Estimated without covariates

\begin{tabular}{|c|c|c|c|c|c|c|c|c|c|c|c|c|}
\hline & \multicolumn{4}{|c|}{ Sickness absence $(A)$} & \multicolumn{4}{|c|}{ Unemployment (B) } & \multicolumn{4}{|c|}{ Disability benefit $(C)$} \\
\hline & \multicolumn{2}{|c|}{ Sassam } & \multicolumn{2}{|c|}{ AM } & \multicolumn{2}{|c|}{ Sassam } & \multicolumn{2}{|c|}{$\mathrm{AM}$} & \multicolumn{2}{|c|}{ Sassam } & \multicolumn{2}{|c|}{ AM } \\
\hline & Odds & St. err & Odds & St. err & Odds & St. err & Odds & St. err & Odds & St. err & Odds & St. err \\
\hline & ratio & & ratio & & ratio & & ratio & & ratio & & ratio & \\
\hline Dec -07 & 1.046 & $(0.046)$ & 0.918 & $(0.067)$ & 0.907 & $(0.084)$ & 1.062 & $(0.123)$ & 2.158 & $(0.866)$ & - & - \\
\hline Jan -08 & 1.079 & $(0.037)^{\star \star}$ & 0.998 & $(0.054)$ & 0.947 & $(0.065)$ & 0.927 & $(0.095)$ & 0.647 & $(0.517)$ & - & - \\
\hline Feb -08 & 1.108 & $(0.035)^{\star \star *}$ & 1.028 & $(0.051)$ & 0.996 & $(0.060)$ & 0.922 & $(0.086)$ & 0.944 & $(0.366)$ & 0.766 & $(0.541)$ \\
\hline Mar -08 & 1.072 & $(0.035)^{\star \star}$ & 1.008 & $(0.050)$ & 0.932 & $(0.057)$ & 0.890 & $(0.084)$ & 1.034 & $(0.292)$ & 1.115 & $(0.418)$ \\
\hline Apr -08 & 1.029 & $(0.034)$ & 1.056 & $(0.050)$ & 0.955 & $(0.056)$ & 0.965 & $(0.081)$ & 1.222 & $(0.223)$ & 1.071 & $(0.306)$ \\
\hline May -08 & 1.056 & $(0.035)$ & 1.050 & $(0.050)$ & 0.954 & $(0.055)$ & 0.930 & $(0.080)$ & 1.135 & $(0.127)$ & 1.090 & $(0.255)$ \\
\hline Jun -08 & 1.070 & $(0.035)^{\star}$ & 1.005 & $(0.051)$ & 0.952 & $(0.054)$ & 0.966 & $(0.078)$ & 1.194 & $(0.177)$ & 1.077 & $(0.187)$ \\
\hline Jul -08 & 1.047 & $(0.036)$ & 0.982 & $(0.052)$ & 0.964 & $(0.053)$ & 0.986 & $(0.077)$ & 1.209 & $(0.101)^{\star}$ & 0.983 & $(0.139)$ \\
\hline Aug -08 & 1.052 & $(0.036)$ & 0.982 & $(0.052)$ & 0.939 & $(0.053)$ & 0.962 & $(0.077)$ & 1.196 & $(0.098)^{*}$ & 1.022 & $(0.135)$ \\
\hline Sep -08 & 1.027 & $(0.037)$ & 0.972 & $(0.053)$ & 0.926 & $(0.052)$ & 0.978 & $(0.076)$ & 1.215 & $(0.095)^{\star \star}$ & 1.058 & $(0.131)$ \\
\hline Oct -08 & 1.032 & $(0.037)$ & 0.956 & $(0.053)$ & 0.951 & $(0.052)$ & 0.973 & $(0.076)$ & 1.192 & $(0.092)^{*}$ & 1.073 & $(0.127)$ \\
\hline Nov -08 & 1.054 & $(0.038)$ & 0.975 & $(0.054)$ & 0.948 & $(0.051)$ & 0.928 & $(0.074)$ & 1.170 & $(0.088)^{*}$ & 1.022 & $(0.123)$ \\
\hline Dec -08 & 1.040 & (0.039) & 0.927 & $(0.055)$ & 0.957 & $(0.050)$ & 0.950 & $(0.072)$ & 1.182 & $(0.086)^{*}$ & 1.052 & $(0.119)$ \\
\hline Jan -09 & 1.049 & $(0.040)$ & 0.934 & $(0.057)$ & 0.967 & $(0.049)$ & 0.897 & $(0.071)$ & 1.156 & $(0.083)^{*}$ & 1.043 & $(0.116)$ \\
\hline Feb -09 & 1.030 & $(0.040)$ & 0.950 & $(0.058)$ & 0.972 & $(0.049)$ & 0.917 & $(0.070)$ & 1.190 & $(0.081)^{\star \star}$ & 1.062 & (0.112) \\
\hline
\end{tabular}

